\title{
Predictors of recurrence and reoperation for prosthetic valve endocarditis after valve replacement surgery for native valve endocarditis
}

Lynn M. Fedoruk, MD, W. R. Eric Jamieson, MD, Hilton Ling, MD, Joan S. MacNab, Eva Germann, MSc, Shahzad S. Karim, MD, and Samuel V. Lichtenstein, MD, PhD

Objective: Surgical treatment of native valve endocarditis remains challenging, especially in cases with paravalvular destruction. Basic principles include complete debridement and reconstruction. This study is designed to evaluate the outcomes of surgical reconstruction of complex annular endocarditis using standard techniques and materials, including autologous and bovine pericardium.

\begin{abstract}
Methods: From 1975 to 2000, 358 cases (357 patients, mean age $49 \pm 16$ years, range 18-88 years) of native valve endocarditis were surgically managed. Bioprosthetic valves were implanted in 189 cases, and mechanical prostheses were implanted in 169 cases. A total of 78 cases of paravalvular destruction were identified: 62 annular abscesses, 8 fistulas, and 8 combined abscesses/fistulas. These were managed with 46 pericardial patches and 32 isolated suture reconstructions after radical debridement and prosthetic valve replacement.
\end{abstract}

Results: The overall early mortality was $8.4 \%(\mathrm{n}=30)$. The mortality with paravalvular destruction was $17.9 \%$, and the mortality with simple leaflet infection was $5.7 \%(P=.001)$. The unadjusted survival at 20 years was $26.4 \% \pm 4.9 \%$ for bioprosthetic valves and $56.5 \% \pm 8.1 \%$ for mechanical prostheses $(P=.007)$. The freedom from recurrent prosthetic valve endocarditis was $78.9 \% \pm 4.4 \%$ at 15 years. The freedom from reoperation for recurrent prosthetic valve endocarditis was $85.8 \% \pm 4.2 \%$ at 15 years. The freedom from reoperation after reconstruction for paravalvular destruction was $88.2 \% \pm 6.9 \%$ at 15 years. The freedom from mortality for recurrent prosthetic valve endocarditis was $92.7 \% \pm 3.4 \%$ at 15 years. The independent predictors of reoperation were age (hazard ratio $0.930, P=.005$ ) and intravenous drug use/human immunodeficiency virus plus surgical technique (hazard ratio $12.8, P=.003$ for patch reconstruction plus valve and hazard ratio $3.6, P=.038$ for valve replacement only). Prosthesis type was not predictive when separated from intravenous drug use/human immunodeficiency virus (hazard ratio $3.268, P=.088$ ).

Conclusion: Paravalvular destruction is associated with a higher operative mortality. Native valve endocarditis can be managed with reasonable long-term survival and low rates of reinfection with radical debridement and pericardial reconstruction with bioprostheses and mechanical prostheses. The type of prosthesis implanted does not influence long-term outcome. Patients with a history of intravenous drug use and human immunodeficiency virus are at increased risk for recurrent infection and reoperation.

Infectious endocarditis that does not resolve with appropriate antibiotic therapy is a complicated problem associated with substantial morbidity and mortality. Approximately one third of patients with endocarditis will require operative intervention. ${ }^{1-3}$ At least $10 \%$ of cases of endocarditis develop paravalvular extension associated with the infection, which adds significant morbidity and complexity to the surgery. ${ }^{4,5}$

The diagnosis of endocarditis requires a multifaceted approach, including clinical, laboratory, and echocardiographic data. The diagnosis of paravalvular extension is

From the University of British Columbia, Vancouver, Canada.

Presented to the Third Biennial Meeting of the Society for Heart Valve Disease June 17-20, 2005.

Received for publication Sept 25, 2007; revisions received June 18, 2008; accepted for publication Aug 7, 2008.

Address for reprints: W. R. Eric Jamieson, MD, 486 Burrard Bldg, St Paul's Hospital, 1081 Burrard St, Vancouver, Canada V6Z 1Y6 (E-mail: eric.jamieson@ubc.ca). J Thorac Cardiovasc Surg 2009; 137:326-33

$0022-5223 / \$ 36.00$

Copyright (c) 2009 by The American Association for Thoracic Surgery doi:10.1016/j.jtcvs.2008.08.024 imprecise. The presence of a new atrioventricular conduction block suggests extension, as may persistent bacteremia, recurrent emboli, or a new pathologic murmur. The advent of echocardiography has improved the quality of preoperative evaluation, with the transesophageal approach being significantly more specific and sensitive than the transthoracic imaging for defining extension and abscess. ${ }^{6,7}$ Color flow Doppler techniques may demonstrate flow patterns consistent with fistula formation, which is specific for extension.

Operative principles of endocarditis include complete debridement of the infected tissues and drainage of abscess cavities followed by restoration of anatomic relationships, including ventriculo-aortic or atrioventricular continuity. In the majority of cases the infection involves only the valve leaflets; however, in cases with paravalvular destruction, complex repair may be required to close acquired defects and reverse hemodynamic abnormalities.

Multiple surgical options have been advanced for complex reconstruction, and previously the literature has favored 

Abbreviations and Acronyms
$\mathrm{AVR}=$ aortic valve replacement
$\mathrm{BP}=$ bioprosthetic
HIV = human immunodeficiency virus
$\mathrm{HR}=$ hazard ratio
IVDU $=$ intravenous drug use
MP $=$ mechanical prosthesis
MVR $=$ mitral valve replacement
NVE = native valve endocarditis
$\mathrm{PVE}=$ prosthetic valve endocarditis

homograft reconstruction because of lower recurrent infection rates and the relative ease of complex repair. ${ }^{8-10}$ Unfortunately, these grafts are not readily available, especially in urgent and emergency settings.

The objective of this study is to examine the short- and long-term outcomes of surgical reconstruction of complex endocarditis using standard materials, including autologous and bovine pericardium and mechanical and bioprosthetic (BP) valves.

\section{PATIENTS AND METHODS}

A retrospective analysis of the prospectively maintained University of British Columbia Cardiac Valve Database from 1975 to 2000 was conducted to identify native valve endocarditis (NVE) cases. Follow-up was conducted periodically through the years with telephone interviews, review of consultative and echocardiographic documentation, and questionnaires to primary care physicians. The University of British Columbia Cardiac Valve Database receives annual renewal from the University of British Columbia Clinical Research Ethics Board, which includes an informed consenting process. A total of 358 cases of endocarditis managed surgically were identified in 357 patients. All operative notes were obtained and re-reviewed to provide details of operative techniques. There were 257 men $(72.0 \%)$ and 100 women $(28.0 \%)$. The average age was $48.8 \pm 15.9$ years (range 18 88 years). The average age was $51.6 \pm 17.3$ years for those with BP valves and $45.6 \pm 13.5$ years for those with mechanical prostheses (MPs) $(P=$ .0003 , BP > MP). For the major portion of time interval from 1975 to 2000, valve repairs were not included in the University of British Columbia Cardiac Valve Database; consequently, native valve repairs were not included in the study.

Before the mid-1980s, endocarditis was diagnosed by classic clinical criteria, including the combination of positive blood cultures, new or changed murmur, fever, and the presence of progressive heart failure because echocardiography was not available at our institutions before that time. ${ }^{11}$ More recently, echocardiographic findings have been incorporated as a standard mode for diagnosis. The definitive diagnosis was confirmed by surgical identification of a vegetation or pathologic or bacteriologic diagnosis of the vegetation. Abscess and fistula formation were diagnosed from the surgical description in the operative note. An abscess was defined as a region of necrosis with purulent material creating a cavity within the annulus or surrounding paravalvular tissue in the setting of valvular infection. A fistula was defined as an abnormal communication between 2 cardiac chambers.

If surgical reconstruction after extensive debridement was required, it was defined as complex, requiring either primary suture repair or patch reconstruction using bovine or autologous pericardium. The type of valve used was determined from the database. Follow-up was $96 \%$ complete. The average follow-up length was $5.5 \pm 5.5$ years. The follow-up was
$6.1 \pm 6.1$ years for BP and $4.9 \pm 4.5$ years for MP $(P=.031 \mathrm{BP}>$ MP). Reinfection was defined as endocarditis of the prosthetic valve. Given the large study time period and number of institutions with purged medical records, the documentation of culture results was incomplete.

The details of the patient population are presented in Tables 1 and 2. The distribution of BP (189) and MP (169) replacements by valve position are as follows: 181 aortic valve replacements (AVRs) (BP 96, MP 85), 107 mitral valve replacements (MVRs) (BP 58, MP 49), 8 tricuspid valve replacement (BP 7, MP 1), and 62 MR (BP 28, MP 34). One patient had 1 MP-AVR and 1 MP-MVR at separate operations. The population included 78 cases $(21 \%)$ of paravalvular destruction. These included 70 cases of annular abscess or abscess \pm fistula and 8 cases of chamber fistula. Table 2 identifies the relationship of abscesses/fistulas by valve position and type of prosthesis used in the reconstruction procedure.

The follow-up of the patient population revealed that 18 patients underwent reoperation for recurrent infection [prosthetic valve endocarditis (PVE)] (Table 3). Of patients who had reoperation for PVE the mean age was $35.2 \pm 11.6$ years $(61.1 \%$ were male and $38.9 \%$ were female). Of the 18 patients, 12 involved AVR, 15 involved bioprostheses, and 10 had a history of intravenous drug use (IVDU) or human immunodeficiency virus (HIV). Of the 10 IVDU/HIV cases of recurrent PVE, 4 were initially reconstructed by patch or suture repair and 6 valve replacements only (Table 1). There were an additional 12 patients with recurrent infection who did not have reoperation or were denied reoperation (Table 3).

\section{Operative Technique}

Patients were placed on cardiopulmonary bypass using standard cardiac surgical techniques for the era. The basic surgical principle used was radical resection of all infected valvular and paravalvular tissue. If the infection was limited to the leaflets, simple resection and valve replacement were used. If the infection had created a small annular abscess, this pocket was often closed primarily with the horizontal mattress sutures that were used to secure the valve prosthesis. The use of pledgets was dependent on surgeon preference. If extension of the infection had occurred, radical resection of all abscess cavities and adjoining structures was performed. Patch reconstruction was then performed to restore anatomic continuity between adjoining structures. Either autologous pericardium or glutaraldehyde-fixed bovine pericardium was used. Fistulas were treated with debridement and suture or patch closure as surgically indicated. The type of valve implanted was based on surgeon preference, as well as standard guidelines including age, anticoagulation risks, patient reliability, and patient preference. All patients were treated with antibiotics for a prolonged period postoperatively.

\section{Statistical Analysis}

Values are expressed as the mean \pm standard deviation unless otherwise indicated. The Kaplan-Meier method was used to determine long-term survival and freedom from reoperation. Quantitative data were compared with an independent samples $t$ test. Comparisons of categoric variables were performed with Fisher's exact test (2 sided), Pearson's chi-square test, or Yates corrected chi-square test as appropriate. An independent statistician performed the analysis.

The risk analysis, univariate and multivariate, was performed to identify the independent predictors of recurrent infection and reoperation for recurrent infection. The risk variables considered were age, gender, valve position, valve type, annular destructive disease, history or presence of IVDU or HIV, and surgical reconstructive technique. Variables with a univariate $P$ value of less than .25 were evaluated in the multivariate modeling.

\section{RESULTS}

The overall operative mortality rate for NVE was $8.4 \%$ $(\mathrm{n}=30)$. In the cohort with paravalvular destruction 
TABLE 1. Patient population: Descriptive statistics

\begin{tabular}{|c|c|c|c|c|}
\hline Variables & Total 358 & NO PVE reoperation $n=340^{c}$ & YES PVE reoperation $n=18$ & $P$ value \\
\hline Age $($ mean $\pm \mathrm{SD})$ & 357 & $49.53 \pm 15.73$ & $35.18 \pm 11.64$ & .0001 \\
\hline Gender (male/female) & 357 & $72.6 \%(246) / 27.4 \%$ (93 patients) & $61.1 \%(11) / 38.9 \%(7)$ & $.291^{\mathrm{b}}$ \\
\hline Valve position & & & & 0.479 \\
\hline AVR & $(181)$ & $49.7 \%(169)$ & $66.7 \%(12)$ & \\
\hline MVR & (106) & $30.3 \%(103)$ & $16.7 \%(3)$ & \\
\hline TVR & (8) & $2.4 \%(8)$ & $0 \%(0)$ & \\
\hline MR & (63) & $17.6 \%(60)$ & $16.7 \%(3)$ & \\
\hline Valve type & & & & $.015^{\mathrm{a}}$ \\
\hline BP & (189) & $51.2 \%(174)$ & $83.3 \%(15)$ & \\
\hline MP & (169) & $48.8 \%(166)$ & $16.7 \%(3)$ & \\
\hline IVDU/HIV & & & & $<.0001^{\mathrm{b}}$ \\
\hline No & $(315)$ & $90.3 \%(307)$ & $44.4 \%(8)$ & \\
\hline Yes & (43) & $9.7 \%(33)$ & $55.6 \%(10)$ & \\
\hline Disease & & & & .430 \\
\hline None & $(280)$ & $77.9 \%(265)$ & $83.3 \%(15)$ & \\
\hline Abscess \pm fistula & (70) & $20.0 \%(68)$ & $11.1 \%(2)$ & \\
\hline Fistula only & (8) & $2.1 \%(7)$ & $5.6 \%$ & \\
\hline IVDU/HIV + technique & & & & $<.0001$ \\
\hline IVDU/HIV: patch + valve & (8) & $1.2 \%(4)$ & $22.2 \%(4)$ & \\
\hline IVDU/HIV: suture + valve & (1) & $0.3 \%(1)$ & $0 \%(0)$ & \\
\hline IVDU/HIV: valve only & (34) & $8.2 \%(28)$ & $33.3 \%(6)$ & \\
\hline NO: patch + valve & (38) & $11.2 \%(38)$ & $0 \%(0)$ & \\
\hline NO: suture + valve & (23) & $6.5 \%(22)$ & $5.6 \%(1)$ & \\
\hline NO: valve only & (254) & $72.6 \%(247)$ & $38.9 \%(7)$ & \\
\hline $\begin{array}{l}\text { Valve type in combination } \\
\text { IVDU + HIV }\end{array}$ & & & & $<.0001$ \\
\hline $1 \mathrm{BP}:$ no IVDU or HIV & (156) & $44.1 \%(150)$ & $33.3 \%(6)$ & \\
\hline $2 \mathrm{MP}:$ no IVDU or HIV & (159) & $46.2 \%(157)$ & $11.1 \%(2)$ & \\
\hline 3 BP: yes IVDU or HIV & (33) & $7.1 \%(24)$ & $50.0 \%(9)$ & \\
\hline 4 MP: yes IVDU or HIV & (10) & $2.6 \%(9)$ & $5.6 \%$ & \\
\hline Surgery technique & & & & .474 \\
\hline Patch + valve & (46) & $12.4 \%(42)$ & $22.2 \%(4)$ & \\
\hline Suture + valve & (32) & $6.8 \%(31)$ & $5.6 \%(1)$ & \\
\hline Valve only & $(280)$ & $80.9 \%$ (267) & $72.2 \%(13)$ & \\
\hline
\end{tabular}

$P V E$, Prosthetic valve endocarditis; $S D$, standard deviation; $A V R$, aortic valve replacement; $M V R$, mitral valve replacement; $M R$, multiple replacement; $B P$, bioprosthetic; $M P$, mechanical prosthesis; TVR, tricuspid valve replacement; $I V D U$, intravenous drug use; $H I V$, human immunodeficiency virus. ${ }^{\mathrm{a}}$ Yates corrected chi-square test. ${ }^{\mathrm{b}}$ Fisher's exact test, 2-tailed. ${ }^{c} \mathrm{n}=340$ (inclusive of 12 with non-reoperative recurrent infection. No marker $=$ Pearson's chi-square test.

$(\mathrm{n}=78)$, the operative mortality was $17.9 \%(14$ AVR, 5 ; MVR, 4; MR, 5) compared with 5.7\% $(\mathrm{n}=16)$ in patients with simple leaflet infection $(P=.001)$. Ninety-eight patients died during follow-up. The overall 10-year survival was $58.2 \% \pm 3.4 \%$. Survival at 15 years was $36.6 \% \pm$ $4.4 \%$ for all patients, and this decreased to $32.6 \% \pm$ $4.8 \%$ by 20 years. The overall predictors of survival were age (hazard ratio [HR] 1.030, $P<.001$ ), IVDU/HIV (HR 3.22, $P=.00003$ ), and patch + valve reconstruction (HR 2.90, $P=.0001$ ).

PVE subsequently developed in 30 patients, with 18 $(5.0 \%)$ managed with reoperation (Table 3 ). Of these 30 cases, $7(23.3 \%)$ occurred in patients who had an abscess or fistula at the time of the initial operation (Table 3). Operative mortality for reoperation was $16.6 \%$ ( 3 cases).

Of the 18 reoperative cases, abscess or fistula was present at the initial operation in 3 cases. Of the 12 non-reoperative cases, 8 died and 4 were alive at latest follow-up. Of the 8 deaths (AVR 6, MR 2), 3 AVR had abscess or fistula at the initial operation. Of the 4 alive, non-reoperative cases (AVR 1, MVR 2, MR 1), 1 MR had abscess at the initial operation.

Overall freedom from recurrent infection was $85.8 \% \pm$ $3.0 \%$ at 10 years and $78.9 \% \pm 4.4 \%$ at 15 years and 66.9 $\pm 8.7 \%$ at 20 years (Figure $1, A[30 / 358]$ ). The freedom

TABLE 2. Location of abscess or fistula and type of valve implanted

\begin{tabular}{lccc}
\hline Position & Bioprosthetic valve & Mechanical valve & Total \\
\hline Aortic & 21 & 24 & 45 \\
Mitral & 13 & 8 & 21 \\
Tricuspid & 1 & 0 & 1 \\
Multiple & 1 & 10 & 11 \\
Total & 36 & 42 & 78 \\
\hline
\end{tabular}


TABLE 3. Summary of recurrent prosthetic valve endocarditis

\begin{tabular}{lcccc}
\hline \multicolumn{5}{c}{ Patients with reoperation $(\mathbf{n}=\mathbf{1 8} / \mathbf{3 0})$} \\
\hline \multirow{5}{*}{ Position } & No. & Abscess & Fistula & Mortality \\
\cline { 2 - 5 } & 12 & 2 & $1^{\mathrm{a}}$ & $3^{\mathrm{a}}$ \\
AVR & 3 & 0 & 0 & 0 \\
MVR & 3 & 0 & 0 & 0 \\
MR & & & &
\end{tabular}

Patients with no reoperation $(n=12 / 30)$

\begin{tabular}{lcccc}
\hline & \multicolumn{4}{c}{ Initial operation } \\
\cline { 2 - 5 } Position & No. & Abscess & Fistula & Mortality \\
\hline AVR & 7 & $3^{\mathrm{b}}$ & - & $6^{\mathrm{b}}$ \\
MVR & 2 & - & 0 & 0 \\
MR & 3 & $1^{\mathrm{c}}$ & - & $2^{\mathrm{c}}$ \\
\hline
\end{tabular}

$A V R$, Aortic valve replacement; $M V R$, mitral valve replacement; $M R$, multiple replacement. ${ }^{\mathrm{a}}$ One previous fistula at initial operation. ${ }^{\mathrm{b}}$ Three previous abscesses at initial operation; all 3 died with recurrent PVE. ${ }^{\circ}$ One previous abscess at initial operation; alive through follow-up.

from recurrent PVE favored MP over BP $(P=.027)$ (Figure 1,B). The freedom from recurrent PVE was not differentiated by the presence or absence of annular destruction (abscess \pm fistula) $(P=.132)$ (Figure $1, C)$. The freedom from reoperation for patients with recurrent PVE was $91.7 \% \pm 2.5 \%$ at 10 years, $85.8 \pm 4.2 \%$ at 15 years, and $72.8 \% \pm 9.3 \%$ at 20 years (Figure 2). The 10-year freedom from reoperation for annular destruction (abscess \pm fistula) was $88.2 \% \pm 6.9 \%$ and for pericardial patch reconstruction was $71.5 \% \pm 14.6 \%$. There was 1 reoperation for isolated suture repair of fistula at 209.5 months. The overall freedom from mortality from recurrent PVE (9/30 events) was 95.7\% $\pm 1.5 \%$ at 10 years and $92.7 \% \pm 3.4 \%$ at 15 and 20 years (Figure 3). Of the 3 mortalities from recurrent operative PVE, 1 died 60 days or less after reoperation and 2 died more than 60 days after reoperation.

Some $51.2 \%$ of patients (189) had a BP valve placed. The operative mortality for this group was $10.0 \%$ compared with $6.5 \%$ for patients who had mechanical valves $(P<.001)$. Patients who had a BP valve were older compared with those with mechanical valves $(51.6 \pm 17.3$ years vs $45.6 \pm 13.4$ years, $P<.001) .66 .0 \%$ of the BP valves were placed in male patients $(P<.001)$, and $83.3 \%$ of the reoperations for reinfection occurred in the BP group. $(P=.015)$. The 10 -year survival was $50.8 \% \pm 4.4 \%$ for those with BP valves and $69.9 \pm 5.0 \%$ for those with mechanical valves $(P=.007)$. The adjusted survival, evaluated by cumulative hazard at the mean of the covariate age, revealed a 10-year survival of $51.1 \% \pm 4.4 \%$ for those with $\mathrm{BP}$ valves and $71.9 \% \pm 5.0 \%$ for those with mechanical valves. The predictors of bioprostheses mortality were age (HR 1.023, $P=$ $.002)$, IVDU/HIV (HR 3.23, $P=.0004$ ), abscess/abscess and fistula (HR 2.21, $P=.010$ ), and patch + valve (HR $2.04, P=.020)$. The predictors of mortality in those with MPs were age (HR 1.054, $P<.0001$ ), multiple replacement

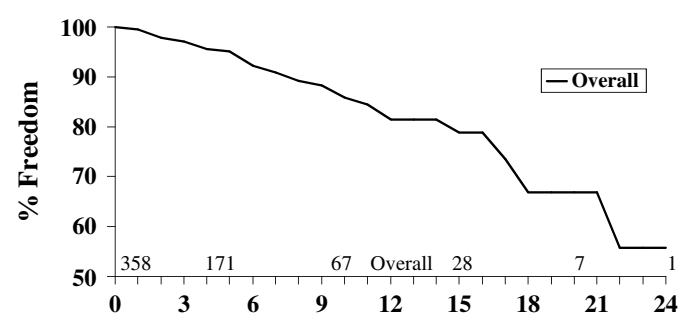

A
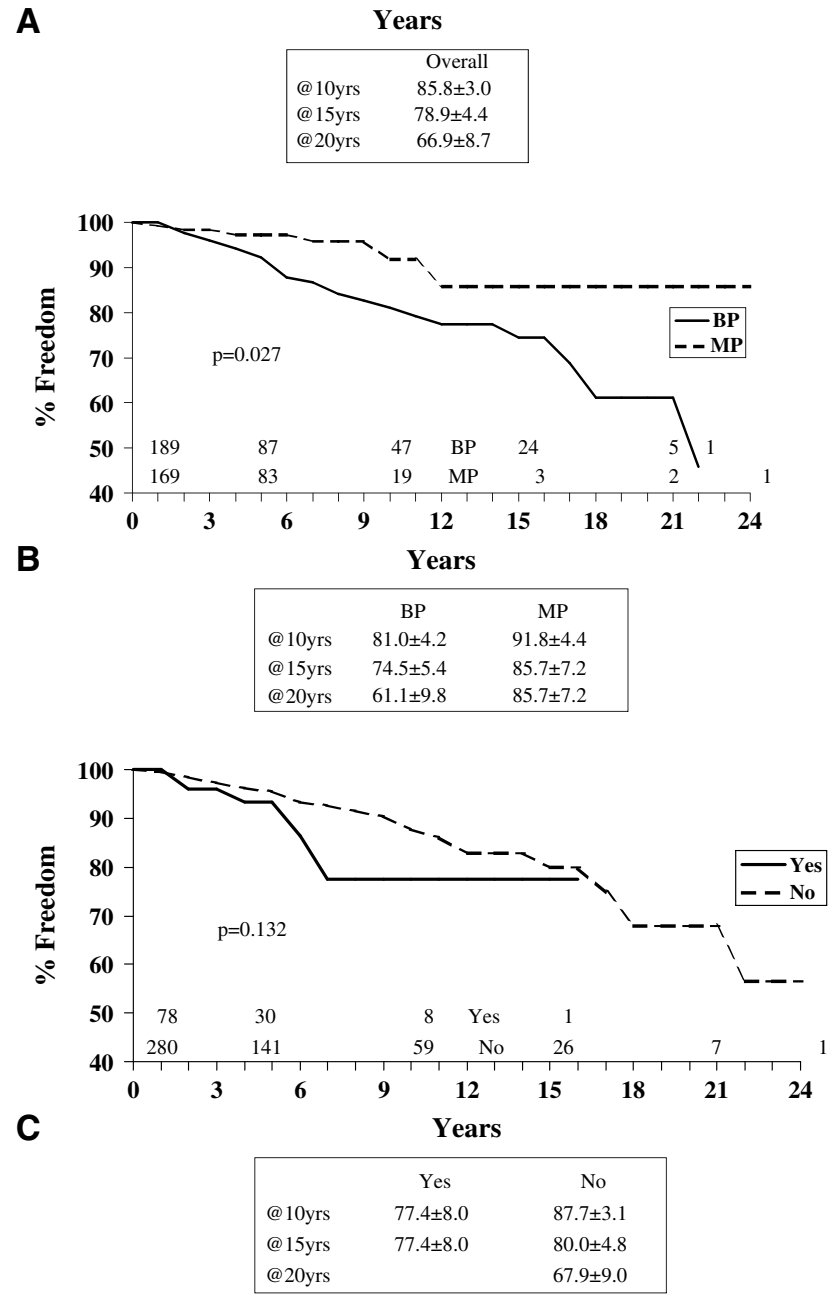

FIGURE 1. A, Freedom from recurrent PVE (overall). B, Freedom from recurrent PVE (prosthesis type). C, Freedom from recurrent PVE (paravalvular destruction). $B P$, Bioprosthetic; $M P$, mechanical prosthesis.

(HR 3.87, $P=.0005)$, and patch + valve reconstruction (HR $2.98, P=.007)$.

Forty-three patients $(16.7 \%)$ in the overall cohort demonstrated IVDU (40) or were HIV positive (3), and 10 of 43 patients $(23.3 \%)$ were involved in $55.6 \%(10 / 18)$ of the reinfections requiring reoperation. There were 46 repairs requiring a pericardial patch overall. All 4 patch repairs that ultimately required reoperation were in the IVDU/HIV cohort.

The patient characteristics are presented in Table 1. The univariate predictors for recurrent infection and reoperation 


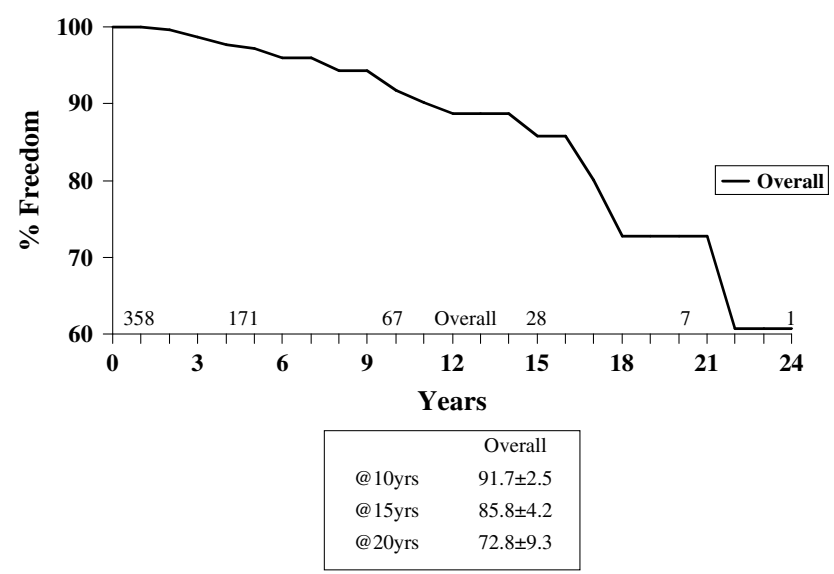

FIGURE 2. Freedom from reoperation for recurrent PVE (overall).

for recurrent infection are detailed in Tables 4 and 5 . The univariate predictors for reoperation for recurrent infection are age (HR 0.93, $P=.001$, protective), valve type $\mathrm{BP}>$ MP (HR 4.77, $P=.015$ ), IVDU/HIV (HR 11.63, $P=$ $.000001)$ IVDU/HIV plus patch plus valve (HR 35.29, $P=.00001)$, IVDU/HIV plus valve only (HR 7.56, $P=$ .001 ), and BP plus IVDU/HIV (HR 9.38, $P=.0001$ ).

The independent predictors of recurrent PVE and recurrent PVE requiring reoperation are detailed in Tables 4 and 5 . The univariate analysis detailed 5 significant predictors in 18 patients. The independent predictors for recurrent infection were: IVDU/HIV + patch + valve (HR 34.3, $P<$ $.00003), \mathrm{IVDU} / \mathrm{HIV}+$ suture + valve (HR 27.4, $P=.003)$ and IVDU/HIV + valve only (HR 5.87, $P<.0001$ ). The independent predictors of reoperation for recurrent PVE were age (HR 0.93, $P=.005$ ), IVDU/HIV plus patch plus valve (HR 12.8, $P=.003$ ), and IVDU/HIV plus valve only (HR $3.6, P=.038)$. Valve type (BP $>\mathrm{MP}$ ) was not predictive for reinfection or reoperation (HR 3.29, $P=.088$ ) by multivariate analysis. The independent predictors of recurrent infection are not appreciably different from those for reoperation for recurrent infection (Tables 4 and 5).

\section{DISCUSSION}

The incidence of infective endocarditis is between 1.7 and 6.2 cases per 100,000 person years and is at least 10 times higher in patients with IVDU. ${ }^{12}$ The first line of therapy is prolonged intravenous antibiotic therapy with a bactericidal agent or agents. Often surgical referral occurs only after failure of the initial antibiotic therapy. The progressive infection leads to significant valvular and paravalvular destruction causing severe regurgitation and acute heart failure. It is estimated that between $10 \%$ and $37 \%$ of patients have some paravalvular complication at the time of surgery. ${ }^{4,13}$ Twenty-two percent of our cohort had paravalvular involvement.

The surgical treatment of endocarditis is associated with substantial morbidity and mortality. The spread of infection

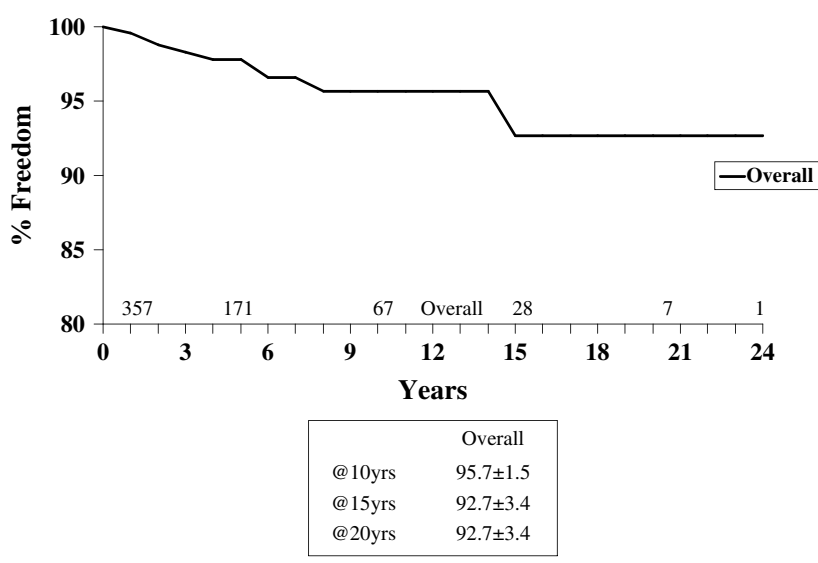

FIGURE 3. Freedom from mortality for recurrent PVE.

from the valve leaflets to the surrounding tissue causes paravalvular destruction, abscess formation, and fistulization. These complications create a complex surgical problem. The required debridement and subsequent restoration of anatomic continuity can be surgically challenging. In the literature, paravalvular infection is associated with a significantly increased mortality and more frequent recurrent rates. ${ }^{5,13,14}$ However, without surgery these patients have a poor outcome, with mortality demonstrated at $100 \%$ in 1 study. ${ }^{15}$ Our study did not demonstrate any increase in recurrence rates in patients with documented paravalvular destruction versus those with only leaflet involvement at 15 years. However, not unlike other studies, there was a significant difference demonstrated in the operative mortality in patients with paravalvular destruction.

The principles of surgical treatment advocated by our group for the treatment of active endocarditis with paravalvular destruction are based on the premise of complete debridement of the infected tissues and drainage of abscess cavities followed by restoration of anatomic relationships, including ventriculo-aortic or atrioventricular continuity. The extensive defects that result from the complete resection of all infected tissue require complex reconstruction in some cases. Ultimately, we believe that the most important surgical principles are based on radical debridement to eradicate the infection and provide acceptable long-term results. This aggressive approach may be responsible for the improved long-term outcomes seen in our study.

The use of homografts has been advocated as the treatment of choice for multiple reasons. ${ }^{8,16,17,18}$ They have flexibility and can be implanted to exclude abscess cavities. Furthermore, the allograft often has a portion of the mitral apparatus attached and provides a larger tissue area. There is an intrinsic resistance to infection reported that is associated with a low rate of recurrent infection. Anticoagulation is not needed as an adjunct after homograft implantation, and therefore the related complications are avoided.

There are, however, several important issues related to homograft use that make other surgical options attractive. 
TABLE 4. Predictors for recurrent infection (univariate analysis and multivariate analyses)

\begin{tabular}{|c|c|c|c|c|}
\hline \multirow[b]{2}{*}{ Independent predictors } & \multicolumn{2}{|c|}{ Univariate } & \multicolumn{2}{|c|}{ Multivariate } \\
\hline & Hazard ratio $(95 \%$ CI $)$ & $P$ value & Hazard ratio $(95 \%$ CI $)$ & $P$ value \\
\hline Age & $0.972(0.948-0.998)$ & .033 & $0.984(0.955-1.015)$ & 0.312 \\
\hline \multicolumn{5}{|l|}{ Gender } \\
\hline Male $>$ female & $1.351(0.627-2.913)$ & .442 & & \\
\hline Valve position & & .497 & & \\
\hline MVR & $0.634(0.234-1.715)$ & .369 & & \\
\hline MR & $1.612(0.635-4.094)$ & .315 & & \\
\hline \multicolumn{5}{|l|}{ Valve type } \\
\hline $\mathrm{BP}>\mathrm{MP}$ & $2.683(1.083-6.644)$ & .033 & $1.891(0.673-5.313)$ & 0.227 \\
\hline \multicolumn{5}{|l|}{ IVDU HIV drug user or HIV } \\
\hline Yes & $13.135(6.246-27.620)$ & $<.0001$ & & \\
\hline Disease & & .334 & & \\
\hline Abscess \pm fistula & $1.910(0.760-4.796)$ & .169 & & \\
\hline Fistula only & $2.030(0.271-15.191)$ & .491 & & \\
\hline $\mathrm{IVDU}+\mathrm{HIV}+\mathrm{Tech}$ & & $<.0001$ & & \\
\hline IVDU/HIV: patch + valve & $51.985(17.913-150.865)$ & $<.0001$ & $34.250(10.674-109.899)$ & $<0.0001$ \\
\hline IVDU/HIV: suture + valve & $22.627(2.838-180.392)$ & .003 & $27.419(3.030-248.154)$ & 0.003 \\
\hline IVDU/HIV: valve only & $7.394(2.946-18.555)$ & $<.0001$ & $5.869(2.225-15.477)$ & 0.0003 \\
\hline NO: patch + valve & - & - & $0.000(0.000)$ & 0.983 \\
\hline NO: suture + valve & $0.719(0.095-5.462)$ & .749 & $0.689(0.089-5.334)$ & 0.721 \\
\hline NO: valve only (baseline) & - & - & - & - \\
\hline Valve type in combination IVDU + HIV & & $<.0001$ & & \\
\hline MP: no IVDU or HIV & $9.375(3.061-28.712)$ & .244 & & \\
\hline BP: yes IVDU or HIV & $12.324(05363-28.318)$ & $<.0001$ & & \\
\hline MP: yes IVDU or HIV & $5.401(1.165-25.035)$ & .031 & & \\
\hline Surgery technique & & .005 & & \\
\hline Patch + valve & $4.726(1.850-12.072)$ & .001 & & \\
\hline Suture + valve & $1.052(0.246-4.504)$ & .945 & & \\
\hline
\end{tabular}

Homografts have a rate of structural valve deterioration similar to that of BP valves. ${ }^{19}$ They have limited availability in many regions, including Canada. Reoperation on an in situ homograft can be challenging. ${ }^{20}$

A recent study using homografts by Sabik and colleagues ${ }^{8}$ from the Cleveland Clinic demonstrated similar outcomes despite significant differences in technique, when compared with our results. The 10-year survival in their study was $56 \%$ compared with our overall 10 -year survival of $58 \%$, and there were no differences in the 10-year freedom from reoperation ( $96 \%$ vs 92\%).

A significant proportion $(16.7 \%)$ of our patient population demonstrated IVDU or were HIV positive. These patients were involved in $55.6 \%$ of the reoperations for reinfection and all of the failed patch repairs that were initially performed to repair abscesses or fistulas. This patient cohort challenges available health care principles because of underlying socioeconomic and mental health issues. They often seek medical attention late in the course of the disease process. This may contribute to this cohort having more extensive infections at initial presentation. Their immunocompromised state likely contributes to this. Compliance with long-term antibiotic therapy is poor, and they often continue to use intravenous drugs. Some $73 \%$ of this cohort had a BP valve implanted, despite being in general a younger patient group because of concerns related to these factors.

Studies examining which valve is better for implantation in light of endocarditis demonstrate equipoise. Moon and colleagues $^{21}$ found no difference in reinfection rates between BP and mechanical valves. Haydock and colleagues ${ }^{22}$ compared homografts with standard valves and found no advantage in either group. Lytle and colleagues ${ }^{24}$ at the Cleveland Clinic also found no difference in rates of reoperation or survival among BP, mechanical, or homograft implantations. A study from the Texas Heart Institute demonstrated an increase in reoperation rates for recurrent endocarditis in patients with BP implantation. ${ }^{23}$

Our study demonstrated a significant increase in the rate of reoperation for reinfection by univariate analysis in patients with a BP valve implanted. However, this difference is negated using multivariate logistic regression. This is most likely because of the common practice of implanting 
TABLE 5. Predictors for reoperation for recurrent infection (univariate and multivariate analyses)

\begin{tabular}{|c|c|c|c|c|}
\hline \multirow[b]{2}{*}{ Independent predictors } & \multicolumn{2}{|c|}{ Univariate } & \multicolumn{2}{|c|}{ Multivariate } \\
\hline & Hazard ratio $(95 \%$ CI) & $P$ value & Hazard ratio $(95 \%$ CI $)$ & $P$ value \\
\hline Age & $0.927(0.887-0.968)$ & .001 & $0.930(0.885-0.978)$ & .005 \\
\hline \multicolumn{5}{|l|}{ Gender } \\
\hline Male $>$ female & $1.665(0.627-4.424)$ & .306 & & \\
\hline \multicolumn{5}{|l|}{ Valve position } \\
\hline MVR & $0.410(0.113-1.488)$ & .175 & & \\
\hline MR & $0.704(0.192-2.581)$ & .597 & & \\
\hline \multicolumn{5}{|l|}{ Valve type } \\
\hline $\mathrm{BP}>\mathrm{MP}$ & $4.770(1.356-16.778)$ & .015 & $3.268(0.838-12.742)$ & .088 \\
\hline \multicolumn{5}{|l|}{ IVDU HIV drug user or HIV } \\
\hline Yes & $11.629(0.4292-31.504)$ & $<.0001$ & & \\
\hline \multicolumn{5}{|l|}{ Disease } \\
\hline Abscess \pm fistula & $0.520(0.116-2.327)$ & .392 & & \\
\hline Fistula only & $2.524(0.291-21.860)$ & .401 & & \\
\hline $\mathrm{IVDU}+\mathrm{HIV}+\mathrm{Tech}$ & & .0002 & & \\
\hline IVDU/HIV: patch + valve & $35.286(7.294-170.696)$ & $<.0001$ & $12.832(2.434-67.655)$ & .003 \\
\hline IVDU/HIV: suture + valve & - & - & - & - \\
\hline IVDU/HIV: valve only & $7.561(2.374-24.080)$ & .001 & $3.632(1.076-12.263)$ & .038 \\
\hline NO: patch + valve & - & - & - & - \\
\hline NO: suture + valve & $1.604(0.189-13.635)$ & .665 & $1.353(0.144-12.743)$ & .792 \\
\hline NO: valve only (baseline) & - & - & - & - \\
\hline Valve type in combination IVDU $+\mathrm{HIV}$ & & $<.0001$ & & \\
\hline MP: no IVDU or HIV & $0.318(0.063-1.603)$ & .165 & & \\
\hline BP: yes IVDU or HIV & $9.375(3.061-28.712)$ & .0001 & & \\
\hline MP: yes IVDU or HIV & $2.778(0.301-25.609)$ & .367 & & \\
\hline \multicolumn{5}{|l|}{ Surgery technique } \\
\hline Patch + valve & $2.015(0.627-6.470)$ & .239 & & \\
\hline Suture + valve & $0.920(0.115-7347)$ & .937 & & \\
\hline
\end{tabular}

$C I$, Confidence interval; $M V R$, mitral valve replacement; $M R$, multiple replacement; $I V D U$, intravenous drug use; $H I V$, human immunodeficiency virus; $M P$, mechanical prosthesis; $B P$, bioprosthetic.

BP valves in patients with a known history of IVDU and HIV. This is not an unexpected finding given the known increase risk that this patient population has for endocarditis. ${ }^{12}$ Our study did not demonstrate a difference in reinfection rates between mechanical and BP valves in the general population using multivariate analysis.

All of the reoperations for reinfection with the patch closure technique for abscesses and fistulas occurred in patients with IVDU. This suggests that the failures related to this technique are significantly influenced by patient factors. Initial failure to seek attention and more extensive infection processes are common in this group of patients. However, these factors may also be surrogate markers for long-term unreliability with respect to the requirement of prolonged antibiotic therapy and risks of reinfection secondary to ongoing intravenous use.

\section{LIMITATIONS}

There are limitations to this study. This evaluation is a retrospective review extending over 25 years, and bioprostheses and MPs were used in a region where homografts were not readily accessible. The indications for surgical interventions were based on classic criteria, but acute and chronic phases were incompletely documented. Given the large study time period and number of institutions with purged medical records, the documentation of culture results was incomplete. The exclusion of valve reconstruction/repair is a major limitation of the study. The University of British Columbia Cardiac Valve Database did not completely record valve reconstructions/repair procedures until 2000 when this study was completed. Regardless, given the historical nature of the study, mitral valve repair was not used widely for the majority of the time frame for this study.

\section{CONCLUSIONS}

Surgery for infective endocarditis is associated with high morbidity and mortality. Patients are referred often only after they have developed significant and severe regurgitation secondary to valvular and paravalvular destruction. This is associated with a higher operative mortality rate. However, despite the increased complexity of repair required for patients with paravalvular involvement, reasonable long-term survival and low rates of reinfection can be obtained using 
standard repair techniques if the principle of radical debridement is followed. We demonstrated that standard techniques are as reliable as reported results for homograft repairs. $\mathrm{Pa}$ tients with a history of IVDU and HIV are at increased risk for reinfection and reoperation.

The authors extend appreciation to Kevin Shillitto and Florence Chan for work in the preparation of the article.

\section{References}

1. Hill EE, Herijgers P, Herregods MC, Peetermans WE. Evolving trends in infective endocarditis. Clin Microbiol Infect. 2006;12:5-12.

2. Heiro M, Helenius H, Mäkilä S, Hohenthal U, Savunen T, Engblom E, et al. Infective endocarditis in a Finnish teaching hospital: a study on 326 episodes treated during 1980-2004. Heart. 2006;92:1457-62.

3. Netzer ROM, Altwegg SC, Zollinger E, Täuber M, Carrel T, Seiler C. Infective endocarditis: determinants of long term outcome. Heart. 2002;88:61-6.

4. Anguera I, Miro JM, Evangelista A, Cabell CH, San Roman JA, Vilacosta I, et al. Periannular complications in infective endocarditis involving native aortic valves. Am J Cardiol. 2006;98:1254-60.

5. David TE, Regesta T, Gavra G, Armstrong S, Maganti MD. Surgical treatment of paravalvular abscess: long-term results. Eur J Cardiothorac Surg. 2007;31:43-8.

6. Chambers HF. Transesophageal echocardiography in endocarditis. Chest. 94;105:333-4.

7. Jacob S, Tong AT. Role of echocardiography in the diagnosis and management of infective endocarditis. Curr Opin Cardiol. 2002;17:478-85.

8. Sabik JF, Lytle BW, Blackstone EH, Marullo AGM, Pettersson GB, Cosgrove DM. Aortic root replacement with cryopreserved allograft for prosthetic valve endocarditis. Ann Thorac Surg. 2002;74:650-9.

9. Lytle BW, Sabik JF, Blackstone EH, Svensson LG, Pettersson GB, Cosgrove DM 3rd. Reoperative cryopreserved root and ascending aorta replacement for acute aortic prosthetic valve endocarditis. Ann Thorac Surg. 2002;74: S1754-7.

10. Knosalla C, Weng Y, Yankah AC, Siniawski H, Hofmeister J, Hammerschmidt R, et al. Surgical treatment of active infective aortic valve endocarditis with associated periannular abscess-11 year results. Eur Heart $J$. 2000;21:490-7.
11. Nomenclature and Criteria for Diagnosis of Disease of the Heart and Great Vessels, 8th edition. The Criteria Committee of the New York Heart Association. Boston: Little Brown; 1979. p. 61.

12. Mylonakis E, Calderwood S. Infective endocarditis in adults. N Engl J Med. 2001; 345:1318.

13. Graupner C, Vilacosta I, San Roma'n JA, Ronderos R, Sarria C, Fernandez C, et al Periannular extension of infective endocarditis. J Am Coll Cardiol. 2002;39:1204-11.

14. Naqvi TZ, Boyatt J, Siegel RJ. Predictors of mortality in paravalvular abscess. $J$ Am Soc Echocardiogr. 2005;18:1404-8.

15. Lerakis S, Taylor WR, Lynch M, Litman CM, Clements SD, Thompson TD et al. The role of transesophageal echocardiography in the diagnosis and management of patients with aortic perivalvular abscesses. Am J Med Sci. 2001 321:152-5.

16. Yankah AC, Pasic M, Klose H, Siniawski H, Weng Y, Hetzer R. Homograft reconstruction of the aortic root for endocarditis with periannular abscess: a 17-year study. Eur J Cardiothorac Surg. 2005;28:69-75.

17. Vogt PR, von Segesser LK, Niederhauser U, Genoni M, Kunzli A, Schneider J, et al. emergency surgery for acute infective aortic valve endocarditis: performance of cryopreserved homografts and mode of failure. Eur J Cardiothorac Surg. 1997; 11:53-61.

18. Mahesh A, Angelini G, Caputo M, Jin XY, Bryan A. Prosthetic valve endocarditis. Ann Thorac Surg. 2005;80:1151-8.

19. Lund O, Chandrasekaran V, Grocott-Mason R, Elwidaa H, Mazhar R, Khaghani Z, et al. Primary aortic valve replacement with allografts over twenty-five years: valve-related and procedure-related determinants of outcome. J Thorac Cardiovasc Surg. 1999;117:77-91.

20. Kaya A, Schepens MA, Morshuis WJ, Heijmen RH, Brutel De La Riviere A Dossche KM. Valve-related events after aortic root replacement with cryopreserved aortic homografts. Ann Thorac Surg. 2005;79:1491-5.

21. Moon MR, Miller DC, Moore KA, Oyer PE, Mitchell RS, Robbins RC, et al Treatment of endocarditis with valve replacement: the question of tissue versus mechanical prosthesis. Ann Thorac Surg. 2001;71:1164-71.

22. Haydock D, Barratt-Boyes B, Macedo T, Kirklin JW, Blackstone E. Aortic valve replacement for active infectious endocarditis in 108 patients. A comparison of freehand allograft valves with mechanical prostheses and bioprostheses. J Thorac Cardiovasc Surg. 1992;103:130-9.

23. Sweeney MS, Reul GJ, Cooley DA, Ott DA, Duncan JM, Frazier OH, et al. Comparison of bioprosthetic and mechanical valve replacement for active endocarditis. J Thorac Cardiovasc Surg. 1985;90:676-80.

24. Lytle BW, Priest BP, Taylor PC, Loop FD, Sapp SK, Stewart RW, et al. Surgica treatment of prosthetic valve endocarditis. J Thorac Cardiovasc Surg. 1996;111: 198-210. 